\title{
TÍTULO: PLANO DE GESTÃO INTEGRADA DE RESÍDUOS SÓLIDOS COMO INSTRUMENTO DE GESTÃO AMBIENTAL PÚBLICA
}

Lucas Chagas Paes de Menezes - lucas_cpm89@ hotmail.com

Escola Politécnica de Pernambuco - UPE.

Ana Rita Fraga Drummond - anaritadrummond@gmail.com

Escola Politécnica de Pernambuco - UPE. 


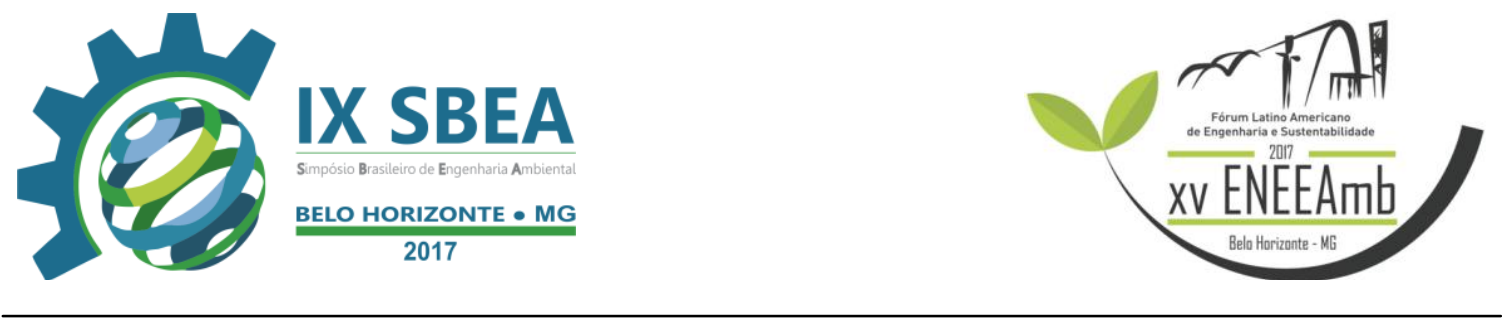

\section{RESUMO}

Este trabalho concentra-se no diagnóstico e proposta de gestão dos Resíduos Sólidos Urbanos (RSU) gerados no município de Panelas, agreste pernambucano. Como resultados do estudo e pesquisa, obteve-se o diagnóstico dos RSU gerados no município, e as diretrizes que nortearão a gestão dos mesmos, assim como ações específicas para cada tipificação de material. Espera-se que a elaboração e aprovação legal deste plano seja o ponto de partida para uma gestão ambiental competente e eficiente, com o desenvolvimento de propostas de trabalho, tanto para a questão dos resíduos sólidos, quanto para questões ambientais gerais, tais como preservação de matas ciliares, implementação de reservas legais e promoção da educação ambiental, com vistas à melhoria da qualidade de vida e saúde da população.

Palavras-chave: Plano de gestão integrada. Gestão Ambiental. Município de Panelas.

\section{INTRODUÇÃO/OBJETIVO}

O Plano de Gestão Integrado de Resíduos Sólidos (PGIRS) é um documento que apresenta a situação atual do sistema de limpeza urbana, estabelecendo alternativas mais viáveis no âmbito municipal e regional, visando ações e diretrizes integradas em todas as fases da gestão de resíduos sólidos, englobando desde a sua geração à disposição final. O PGIRS proposto neste artigo pretende subsidiar o poder público na solução dos seus problemas na área de saneamento ambiental, como também no fortalecimento institucional, propondo modelos gerenciais compatíveis com a realidade do município. Portanto, os principais objetivos deste trabalho são:

\subsection{Objetivo geral}

Mapear os resíduos sólidos no município de Panelas considerando dados sobre coleta, composição e disposição final, visando o diagnóstico, para proposição de estratégia de gestão.

\subsection{Objetivos específicos}

- Levantar as características sociodemográficas e a situação ambiental do município com relação aos resíduos sólidos; 


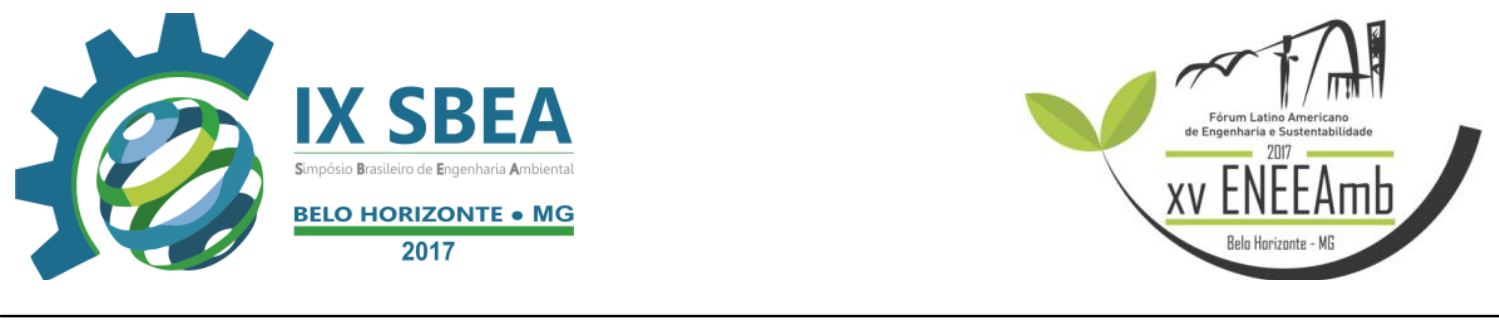

- Propor destinações ambientalmente adequadas para cada tipo RSU gerado pelo município;

- Fomentar a cooperação entre municípios consorciados para a gestão dos RSU;

- Disseminar tecnologias simplificadas de gestão dos RSU através de educação ambiental.

\section{METODOLOGIA}

Os trabalhos para a elaboração do PGIRS foram estruturados por etapas:

\subsection{PRIMEIRA ETAPA - LEVANTAMENTO DE DADOS} BIBLIOGRÁFICOS E DE CAMPO.

Foram realizadas visitas técnicas nos diversos setores do município, incluindo seus distritos e povoados, lixões, terrenos baldios na parte urbana e rural, fronteiras com outros municípios, leitos de rios da região. Foram relatadas as condições da gestão dos resíduos sólidos, desde a sua geração em hospitais, comércio, residências, feiras livres, cemitério, entre outros, até sua disposição final, e os meios para o tal fim. Entre as visitas técnicas, é importante ressaltar a realizada em Agrestina, cidade sede do Consórcio Intermunicipal dos Municípios do Agreste e Mata Sul (COMAGSUL). Aqui foram esclarecidas dúvidas e acrescido informações sobre as ações desenvolvidas por esse consórcio intermunicipal, do qual o município de Panelas faz parte. Outra visita importante foi ao aterro sanitário consorciado, no município de Altinho. Apesar do município de Panelas estar incluído no COMAGSUL, devido à pendencias documentais e políticas, bem como a ausência de um PGIRS municipal, os resíduos sólidos não podem ser destinados ao aterro consorciado.

\subsection{SEGUNDA ETAPA - PROPOSTA PARA O GESTÃO DOS RSU.}

Tendo conhecimento da realidade das diversas dimensões do sistema de limpeza urbana do município, foram realizadas proposições para a gestão dos resíduos sólidos, no que concerne a redução de resíduos na fonte geradora e educação ambiental, prétratamento, acondicionamento, estocagem temporária, coleta/transporte dos resíduos, disposição final e educação ambiental (MMA, 2011). 


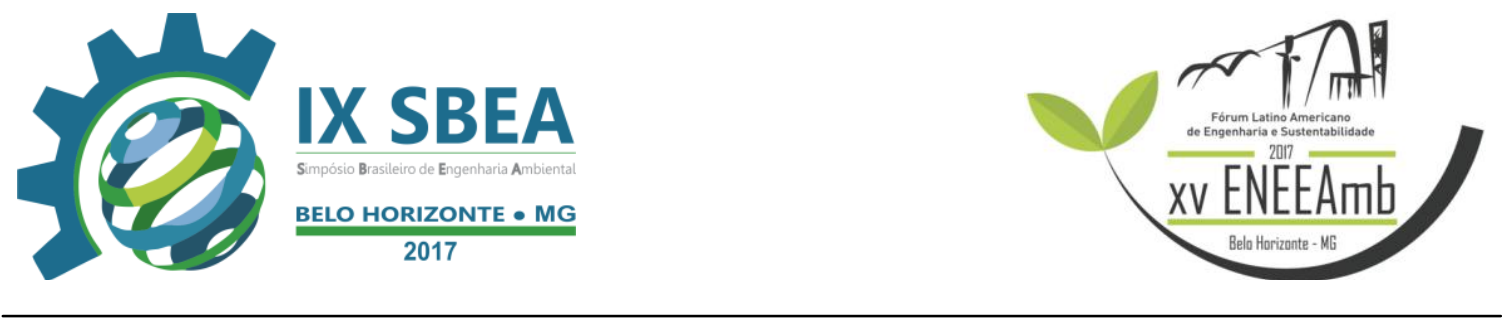

Sendo assim, é importante acrescentar que todo esse processo de trabalho de pesquisa tem como finalidade entregar ao gestor do município um plano de gestão de resíduos sólidos adequado à realidade e necessidades deste município.

\section{RESULTADOS E DISCUSSÃO}

4.1 Resultados da Primeira Etapa

O município de Panelas, distante $201 \mathrm{~km}$ da capital Recife, está localizado na mesorregião Agreste do Estado de Pernambuco. Situa-se na região de desenvolvimento Agreste Central, ocupando 368,1 km² (0,37\% do Estado). Em 2010, a população estimada era de 26.645 habitantes, sendo 13.964 (54,5\%) na zona urbana e 11.681 (45,5\%) na zona rural, e densidade demográfica de 70,3 hab $/ \mathrm{km}^{2}$ (IBGE, 2010).

O Plano Estadual de Resíduos Sólidos de Pernambuco (PERS) mostra a avaliação do panorama da composição dos RSU nos municípios pernambucanos. Foram analisados os percentuais de vidro, metal, plástico e papel, material orgânico e rejeito, de forma a identificar o potencial de material reciclável encontrado na massa de resíduos produzidos. Essa avaliação é importante para a valorização da coleta seletiva, uma vez que o Estado perde cerca de $\mathrm{R} \$ 40$ milhões por mês com a falta de comercialização dos produtos recicláveis, assim como perde bastante espaço com a destinação final, uma vez que apenas os rejeitos devem ser dispostos adequadamente na natureza (SEMAS, 2012).

Gráfico 1 - Composição gravimétrica dos resíduos sólidos de Panelas

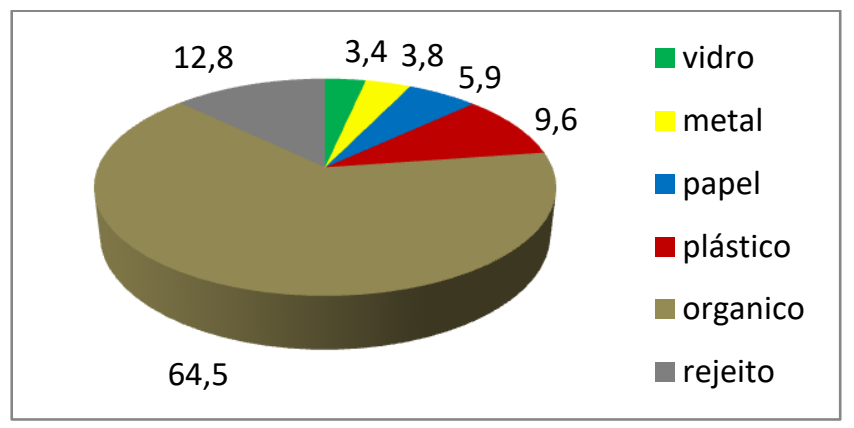

Fonte: SEMAS, 2012. 


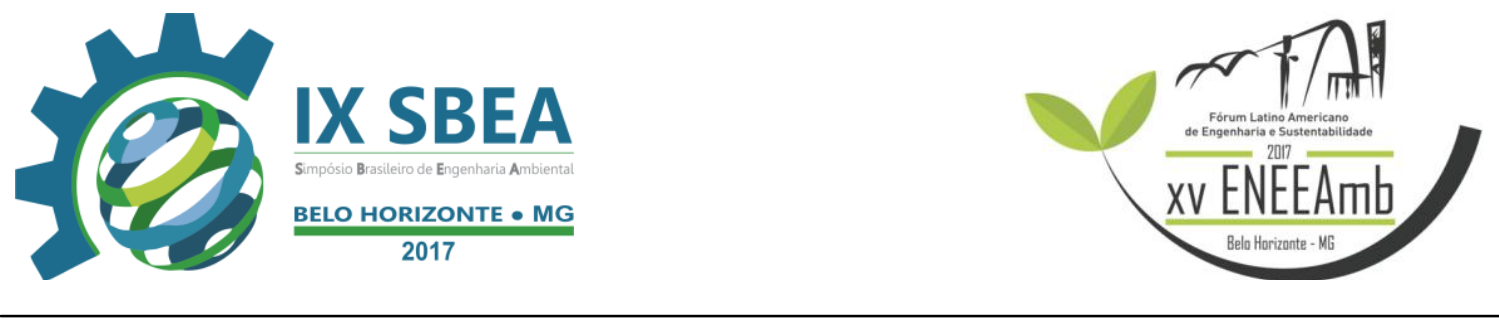

Os resíduos sólidos, quanto à sua origem, seguem o que determina a Lei $\mathrm{n}^{\circ}$ 12.305 (BRASIL, 2010). Quanto a sua natureza, o resíduo pode ser dividido em dois tipos: seco e molhado (GUARNIERI, 2011). Dentre os resíduos molhados estão restos de comida, cascas de frutas ou vegetais (matéria orgânica em geral), e os resíduos secos podem ser divididos em recicláveis como papel, plástico, metal e vidro, e em não recicláveis, chamados de rejeitos. Os resíduos coletados na área de estudo foram analisados segundo essas duas características.

Pode ser observado no gráfico que o percentual de materiais recicláveis em Panelas é de $22,9 \%$ e o de matéria orgânica de $64,5 \%$. É importante e vantajoso para o município investir em formas de tratar seus resíduos, principalmente o resíduo orgânico, que representa mais da metade dos resíduos gerados.

A Secretaria de Infraestrutura de Panelas é o órgão responsável, onde o Coordenador de Limpeza Urbana trabalha no gestão e fiscalização dos serviços de limpeza pública. Foram verificados a frequência e forma de coleta dos resíduos no distrito-sede e nos distritos, vilas e povoados.

Os resíduos sólidos urbanos coletados em Panelas são destinados a um vazadouro a céu aberto (lixão), localizado no perímetro urbano da sede municipal, às margens da estrada PE-158, próximo à Escola Estadual de Referência, à Secretaria de Desenvolvimento e Turismo, e ao campo de futebol do município (Figuras 1 a 4). E por causa da sua localização for considerado como lixão de alto impacto ambiental negativo, segundo Jucá et. al (2011). Com relação a resíduos hospitalares, o principal hospital municipal tem contrato com uma empresa terceirizada para destinar seus resíduos, porém resíduos de clínicas da cidade seguem junto com o resíduo comum. O município não possui matadouro.

No lixão são depositados resíduos de características domiciliares, Classe II. Foram encontrados tanto o lixo orgânico como resíduos de difícil decomposição, sendo eles embalagens de plástico, papel, metal, vidro e pneus. Foram encontrados animais habitando o lixão, assim como catadores informais. 


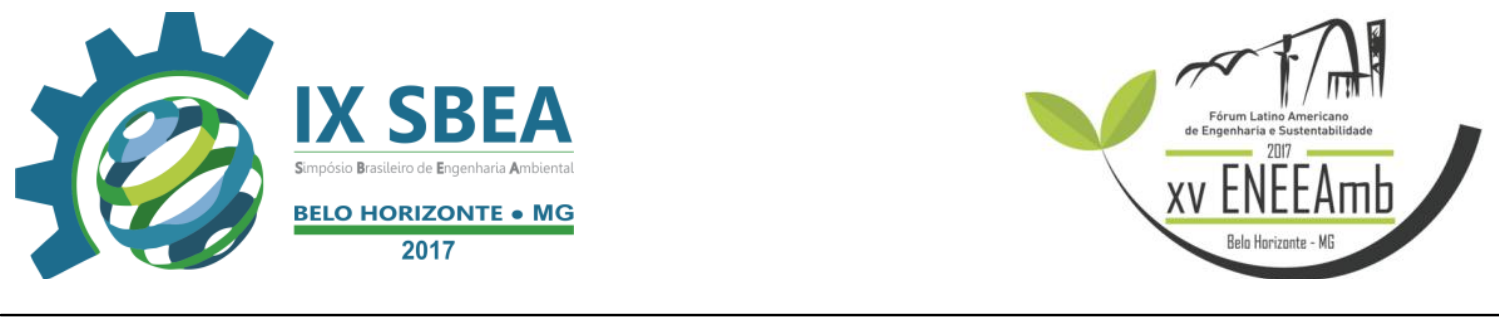

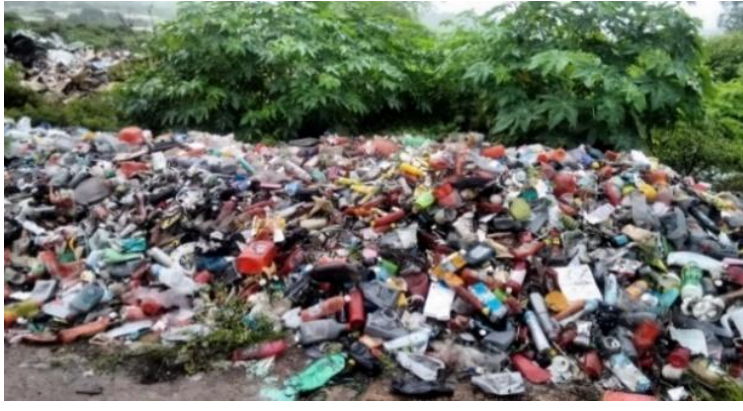

Figura 1 - Lixão de Panelas

Fonte: Equipe técnica, 2015

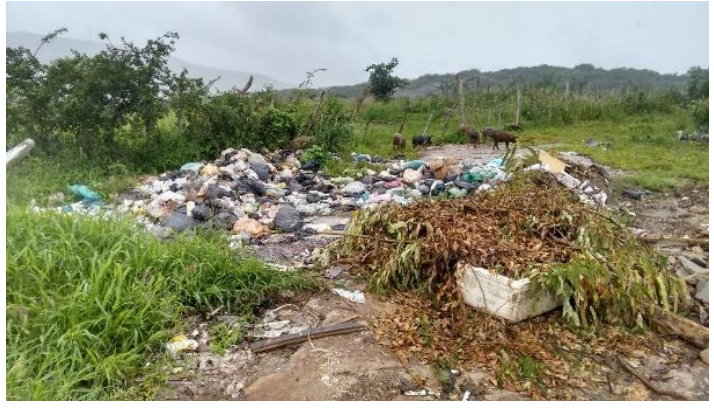

Figura 2 - Presença de animas no lixão

Fonte: Equipe técnica, 2015

Esse vazadouro a céu aberto atrai dois grandes grupos de seres vivos - os macro vetores (mosquitos, moscas, baratas, ratos, porcos, cachorros, urubus, etc.) e os micro vetores (bactérias, fungos e vírus), considerados de grande perigo epidemiológico, principalmente aos catadores que trabalham diretamente no local. Esse fato interfere na qualidade de vida e nas condições de higiene e saúde da população da sede urbana de Panelas, pelo fato do lixão estar praticamente dentro da cidade.

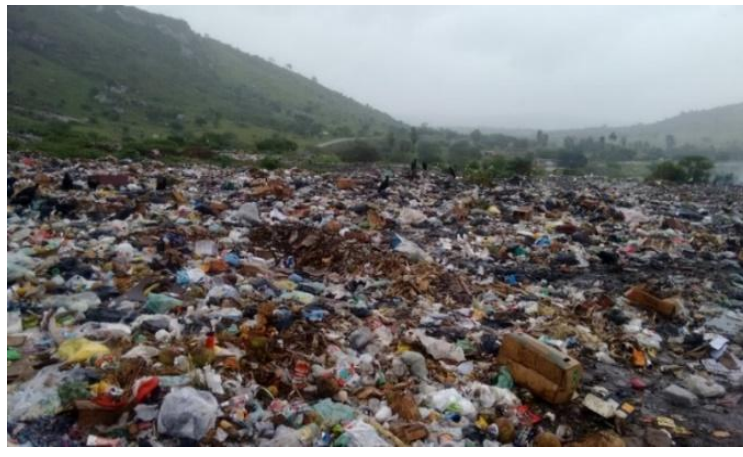

Figura 3 - Lixão de Panelas

Fonte: Equipe técnica

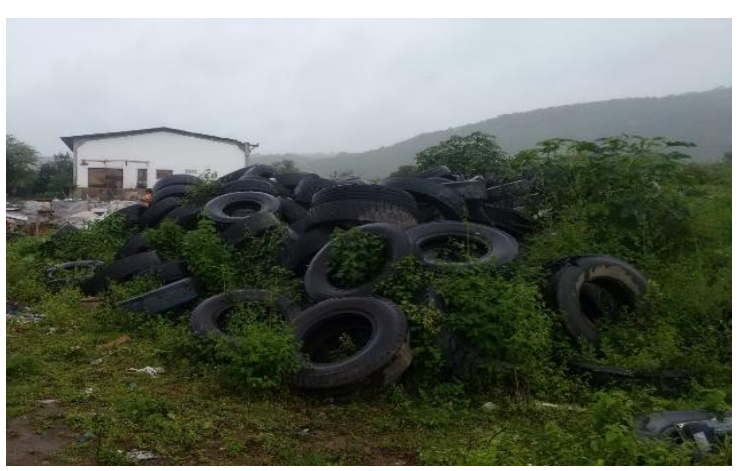

Figura 4 - Presença de pneus Fonte: Equipe técnica

4.2 Resultados da Segunda etapa - Propostas para gerenciamento dos RSU

A gestão dos RSU inclui os caminhos percorridos pelos resíduos sólidos, o financiamento do sistema de limpeza pública, e a característica dos recursos humanos no sistema. Por isso, deve ser pensada desde a fase da sua geração, ou seja, nos -demicíliose 


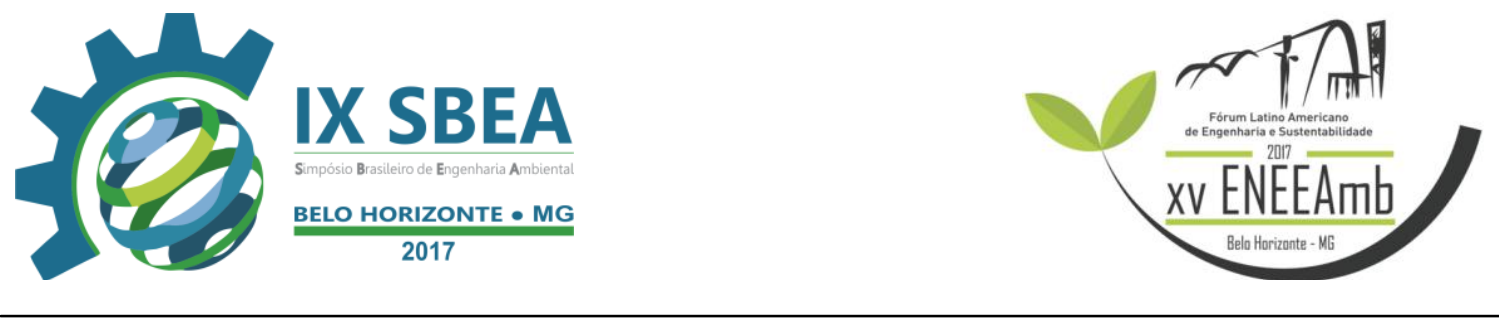

estabelecimentos, até a disposição e destinação final ambientalmente adequadas.

O pré-tratamento é uma etapa muito importante, pois é nesta etapa que ocorre o processo de valorização dos resíduos. Cada tipo de resíduo possui seu pré-tratamento específico. Por exemplo, resíduos recicláveis como plástico, vidro e metal, devem ser limpos/lavados e acondicionados separadamente. Os vários tipos de papel, papelão e similares devem ser segregados. Resíduos de construção e demolição separados e acondicionados (JARDIM et al., 1995), assim como os resíduos especiais, durante as fases da obra ou em estabelecimentos ligados à atividade geradora. O município precisa fazer uma lista de estabelecimentos que podem receber esses resíduos, acondicionar e destinados a uma usina de reciclagem de Resíduos da Construção Civil (RCC).

O acondicionamento é a colocação dos RSU no interior de recipientes apropriados, revestidos, e que garantam sua estanqueidade, em condições regulares de higiene, visando a sua posterior estocagem e coleta (JARDIM et al., 1995).

No processo de tratamento dos resíduos sólidos, é ideal que exista a etapa de transbordo, que é a separação do resíduo sólido coletado, no caso um Centro de Triagem para separação seletiva de materiais recicláveis, com beneficiamento e comercialização realizada pelos agentes ambientais que devem ser organizados em associação (JARDIM et al., 1995).

A Política Nacional de Resíduos Sólidos prioriza a participação dos catadores, pessoas que, nas economias periféricas das grandes e pequenas cidades, estão sobrevivendo do lixo. Eles são essenciais para o fim dos lixões e a implantação da coleta seletiva dos municípios, o que significa menos poluição e mais geração de renda. É importante que o município realize o cadastramento desses trabalhadores, formalizando sua atividade como agente de limpeza urbana, e proponha melhores condições de trabalho (CNMP, 2014). O municio precisa criar uma área de triagem de resíduos sólidos, onde esses agentes possam trabalham em condições salutares. 


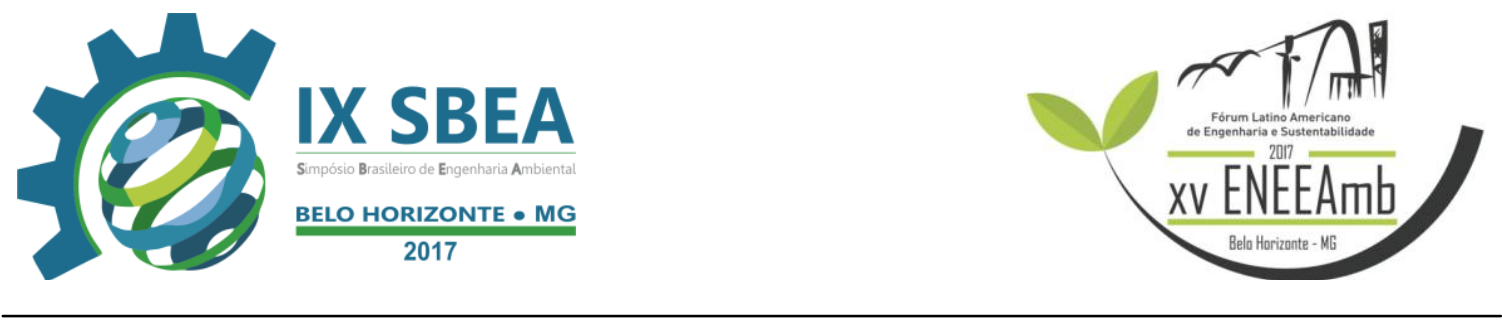

\section{Proposições para o sistema da limpeza pública}

Foram sugeridas propostas adequadas à realidade local, para o sistema de limpeza pública do município. Sugeridas também propostas operacionais, que incluem o suporte físico das instalações existentes e equipamentos utilizados, as tecnologias empregadas e disponíveis para os serviços de limpeza urbana e os processos de operação usados na execução destas funções. Também incluídas propostas para a coleta dos resíduos, tanto domiciliares quanto resíduos da varrição pública, que devem ser feitas mecanizada e com regularidade determinada pelo município.

Deve ser criado um setor de limpeza pública aparte da secretaria de infraestrutura, que será responsável pelos serviços de coleta, limpeza de vias e logradouros, varrição e operações especiais, e um setor de planejamento e controle responsável pela implantação, controle, monitoramento e avaliação dos serviços, e que auxilie inclusive a formação de um programa de coleta seletiva.

Foi percebido também que a Taxa de Limpeza Urbana, incluída no IPTU dos moradores, é a principal fonte que financia o sistema de limpeza pública, uma vez que o município não recebe repasse financeiro voltado para a gestão ambiental. O que dificulta a melhoria da gestão, uma vez que o valor arrecadado é baixo, e existe inadimplência de alguns moradores. O município fica dependente de repasses do estado.

\section{Gestão dos RSU}

Para os resíduos recicláveis, a Coleta Seletiva deve ser empregada, pois permite o recolhimento diferenciado de materiais recicláveis por catadores, sucateiros, entidades sociais e outras, e com o envolvimento de toda a sociedade. Destacou-se a importância da utilização de Ecopontos, para que a população se encarregue da deposição dos materiais recicláveis, enquanto as associações ou cooperativas de catadores seriam responsáveis por coletar o material depositado nessas unidades e levá-los até uma unidade de triagem.

Com relação aos resíduos verdes, estes devem ser separados e encaminhados para produção de adubo, ou apenas estocada para posterior coleta e destinação final (JARDIM et al., 1995). Como a maior porcentagem de resíduos gerados no município é 


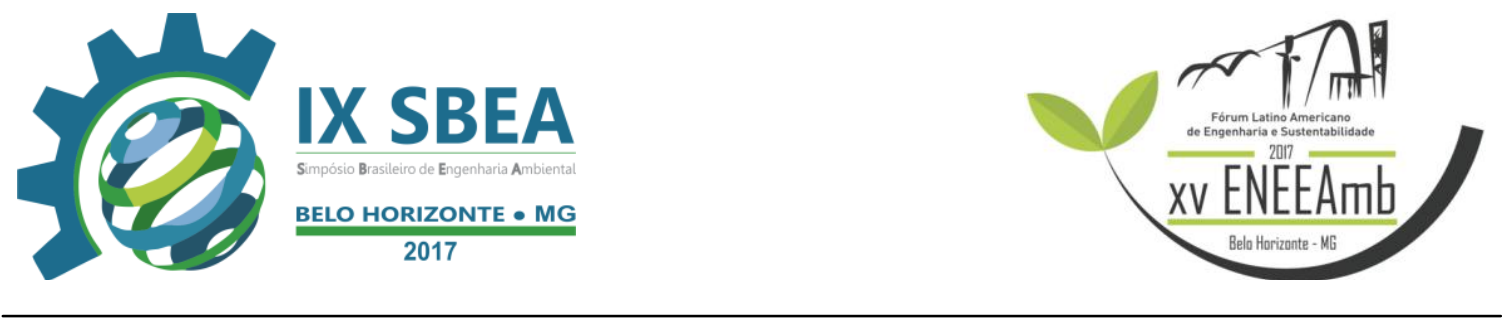

verde, é possível diminuir o volume de resíduos destinados ao aterro sanitário, e o custo que o município teria com a logística e repasses mensais ao consórcio intermunicipal de RSU poderia ser revertido para outras atividades da limpeza urbana. Devem ser escolhidas áreas onde possam ser feitas unidades de compostagem, como escolas rurais, e a secretaria de Agricultura do município, envolvendo a comunidade, professores e alunos. Assim também como biodigestores, uma vez que o PERS também aborda a valorização energética dos resíduos sólidos como uma de suas principais diretrizes.

Os resíduos de saúde e da construção civil, devem ter sua separação, acondicionamento e tratamento final de acordo com as normas e resoluções específicas. Os empreendimentos de serviços de saúde devem ser registrados, e os resíduos, encaminhados a uma empresa responsável e licenciada.

No caso dos resíduos especiais (eletrônicos, pneus, lâmpadas, óleos e graxas, e embalagens de agrotóxicos), é interessante a implantação da Logística Reversa, instrumento de desenvolvimento econômico e social, em que a responsabilidade do ciclo de vida dos resíduos é compartilhada. Ela exige um conjunto de ações que viabilizem a coleta e a restituição dos resíduos sólidos ao setor empresarial. Essas ações contemplam tanto o consumidor comum, sendo obrigado a devolver esses resíduos, quanto os comerciantes e distribuidores devem recebê-los e encaminhá-los aos fabricantes e importadores. Para isso é preciso estabelecer contratos com os fabricantes e estabelecimentos que possam receber esses resíduos.

O PGIRS, uma vez aprovado, tem força de lei, e deve ser executado. Tem de ser periodicamente revisto, verificando o atendimento aos objetivos propostos, resultados alcançados, e ações que devem ser tomadas para a correção e melhoria dos processos de gestão.

\section{CONCLUSÕES/RECOMENDAÇÕES}

O município de Panelas ainda não tem caminhado em direção ao seu enquadramento na Política Nacional de Resíduos Sólidos, principalmente pelas questões de recursos financeiros, humanos, e interesse político. Defende-se a necessidade de 


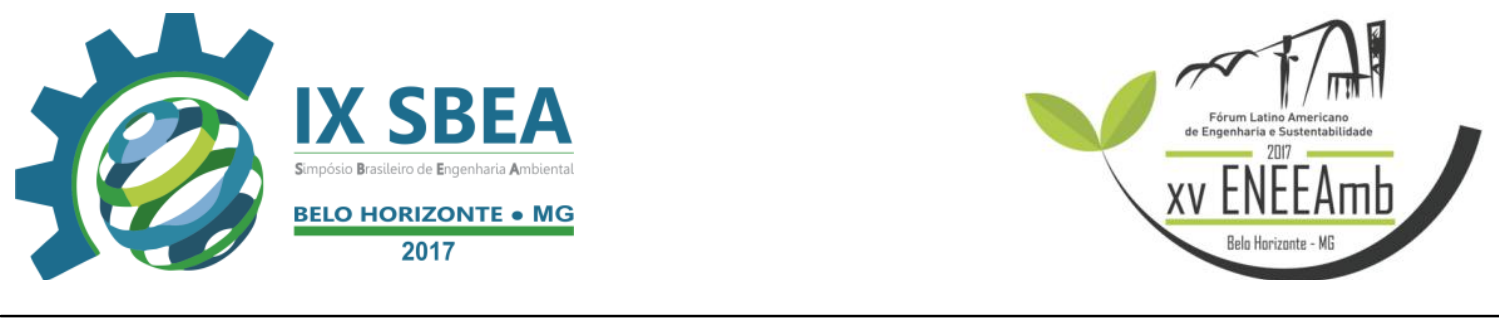

maiores esforços nas áreas de educação ambiental, saúde pública, e comunicação, utilizando-se de mídias locais e outros atores sociais. Deve-se promover sua interrelação com os municípios vizinhos e consorciados, implantando melhorias no sistema de coleta dos resíduos da região em que os municípios estão inseridos. Espera-se que esse estudo possa facilitar esse enquadramento do município, nas políticas de gestão, refletindo na melhoria da qualidade da saúde e de vida da população.

\section{REFERÊNCIAS BIBLIOGRÁFICAS}

CNMP. Conselho Nacional do Ministério Público. Encerramento dos Lixões e a Inclusão Social e Produtiva das Catadoras e Catadores de Materiais Recicláveis. Brasília, 2014.

IBGE. Instituto Brasileiro de Geografia e Estatística. Pesquisa Nacional de Saneamento Básico 2008. Disponível em: http://www.ibge.gov.br/cidadesat. Acesso em: 17 abr. 2016.

JARDIM, N. S. et al. (Org.). Lixo Municipal: manual de gerenciamento integrado. São Paulo: Instituto de Pesquisas Tecnológicas. CEMPRE, 1995.

JUCÁ, J. F. T.; MARIANO, M. O. H..; CAVALCANTI, R. C.; SOBREIRA, A. Diagnóstico de resíduos sólidos no estado de Pernambuco. In: Congresso Brasileiro de Engenharia Sanitária e Ambiental, 21, 12-18 de Setembro, João Pessoa, PB, 2001.

BRASIL. Lei $\mathbf{n}^{\circ}$ 12.305, de 02 de agosto de 2010. Institui a Política Nacional de Resíduos Sólidos, e altera a Lei $\mathrm{n}^{\circ}$ 9.605, de 12 de fevereiro de 1998, e dá outras providências.

MMA. Ministério de Meio Ambiente. Guia de elaboração dos planos de gestão de resíduos sólidos. Brasília, 2011.

PHILIPPI JR., A.; MAGLIO, I. C. Avaliação de Impacto Ambiental: Diretrizes e Métodos. In: PHILIPPI JR. (Ed.). Saneamento, Saúde e Ambiente. Barueri, São Paulo, 2005.

PANELAS. Localização do município de Panelas. Disponível em: <http://www.panelaspernambuco.com/p/localizacao.html>. Acesso em: 26 nov. 2016.

SEMAS. Secretaria de Meio Ambiente e Sustentabilidade. Plano Estadual de Resíduos Sólidos de Pernambuco. 2012. 
ZANTA, V. M.; FERREIRA, C. F. A. Gerenciamento Integrado de Resíduos Sólidos urbanos. Disponível em: http://limpezapublica.com.br/textos/livroprosab.pdf. Acesso em: 20 mar. 2016. 